\title{
Rab-mediated vesicular transport is required for neuronal positioning in the developing Drosophila visual system
}

\author{
Tarek Houalla, Lei Shi, Donald J van Meyel and Yong Rao*
}

\begin{abstract}
Background: The establishment of tissue architecture in the nervous system requires the proper migration and positioning of newly born neurons during embryonic development. Defects in nuclear translocation, a key process in neuronal positioning, are associated with brain diseases such as lissencephaly in humans. Accumulated evidence suggests that the molecular mechanisms controlling neuronal movement are conserved throughout evolution. While the initial events of neuronal migration have been extensively studied, less is known about the molecular details underlying the establishment of neuronal architecture after initial migration.

Results: In a search for novel players in the control of photoreceptor (R cell) positioning in the developing fly visual system, we found that misexpression of the RabGAP RN-Tre disrupted the apical localization of R-cell nuclei. RN-Tre interacts with Rab5 and Rab11 in the fly eye. Genetic analysis shows that Rab5, Shi and Rab11 are required for maintaining apical localization of R-cell nuclei.
\end{abstract}

Conclusions: We propose that Rab5, Shi and Rab11 function together in a vesicular transport pathway for regulating R-cell positioning in the developing eye.

\section{Background}

Normal brain function requires the proper formation of neuronal architecture during development. After birth, many neuronal precursor cells need to undergo long-distance migration to reach their destination [1-3]. Upon reaching correct brain regions, neuronal precursor cells undergo further morphological changes to organize themselves into discrete layers or clusters, differentiate, and elaborate precise connections with their target cells [4]. Neuronal movement occurs in several steps. First, a neuron extends a leading process or neurite that explores the environment for navigational cues [5-7]. Then, following the consolidation of the leading process, the nucleus is translocated into the leading process (i.e. nucleokinesis), which is closely followed by the retraction of the trailing process [8-11].

\footnotetext{
* Correspondence: yong.rao@mcgill.ca

${ }^{1}$ McGill Centre for Research in Neuroscience, Department of Neurology and Neurosurgery, Department of Medicine, McGill University Health Centre, 1650 Cedar Avenue, Montreal, Quebec H3G 1A4, Canada

Full list of author information is available at the end of the article
}

Accumulated evidence support the importance of nuclear translocation in neuronal positioning during development. For instance, defects in nuclear translocation have been suggested to be responsible for the failure of newly born neurons to migrate to the cortical surface during development, leading to abnormal brain structures and mental retardation in Lissencephaly patients $[12,13]$. The molecular mechanism regulating nuclear translocation in neuronal migration appears to be conserved throughout evolution. Lis1, the corresponding gene of Lissencephaly $[14,15]$, has been shown to be evolutionarily conserved, whose orthologues have been identified in organisms like aspergillus nidulans [16] and Drosophila $[17,18]$. Lis-1 interacts with components of the evolutionarily conserved migratory machinery including microtubules [19], the minus-end directed motor protein dynein [16-18] as well as several dyneinassociated proteins such as NUDE [20], NUDC [21] and NUDL [22,23].

The translocation of photoreceptor ( $\mathrm{R}$ cell) nuclei in the developing Drosophila visual system has been proven to be an excellent model system for genetic dissection of the 
general mechanisms controlling neuronal positioning during development [18,24-26]. The development of the Drosophila adult compound eye begins at the third-instar larval stage, when precursor cells differentiate into R cells in the eye-imaginal disc. The eye disc has a single-layered epithelial structure in which cells are continuous from the apical surface to the basal surface, while the nuclei of the cells undergo dynamic translocation. The development of eye disc is marked by the posterior-to-anterior movement of the morphogenetic furrow across the eye disc. The movement of the furrow involves cycles of dynamic cell movement along the apical-basal axis. Initially, anterior precursor cell bodies and nuclei translocate basally, leading to the formation of the furrow. After exiting the furrow, precursor cells begin to differentiate into R cells sequentially, and the nuclei of differentiating $\mathrm{R}$ cells translocate apically [27]. Genetic dissection of R-cell nuclear translocation has shown that this process utilizes evolutionarily conserved mechanisms. For instance, DLis, the Drosophila homolog of human Lis-1, is required for the apical translocation of R-cell nuclei [18]. Apical translocation of R-cell nuclei also requires evolutionarily conserved genes such as dynactin [28,29], klarsicht $[24,30]$, nuclear lamin [31], Bicaudal-D (Bic-D) [18,25], Misshapen (Msn) [25], and Klaroid [26].

While much is known about the control of the initial basal-to-apical translocation of R-cell nuclei, less is known about how apical localization of R-cell nuclei is maintained during development. In a search for novel players in the control of R-cell positioning, we found that misexpression of the fly homolog of the mammalian Rab GTPase-activating-protein (GAP) RN-Tre caused a failure of R-cell nuclei to maintain their apical localization in the developing eye. Mammalian cell culture studies show that RN-Tre can negatively regulate Rab proteins $[32,33]$. Since Rabs are important regulators of intracellular vesicular transport [34], we set out to determine the nature of vesicular transport that is required for the maintenance of R-cell apical localization. Our results support the involvement of a Rab5-Shibire/dynamin-Rab11-dependent vesicular transport pathway in R-cell positioning.

\section{Methods}

\section{Genetics}

GMR-GAL4, EyGAL4 and UY333 lines were provided by the Bloomington Drosophila stock center. GS lines containing bi-directional UAS elements were generated by remobilizing the $\mathrm{P}\{\mathrm{GS} 1\}$ P element $[35,36]$. Rab5 ${ }^{2}$, FRT 40 was provided by D.Bilder. Rab5S43N was provided by M. Gonzalez-Gaitan. UAS-shi ${ }^{1}$ was provided by Y. Zhong. $R a b 11^{\mathrm{ex} 2}$ and Rab11 $\mathrm{ex}$ were provided by R.S. Cohen. UAS-Rab11-RNAi was provided by D.F. Ready. Rab6 ${ }^{\mathrm{D} 23 \mathrm{D}}$ was provided by A. Guichet. Rab5 ${ }^{2}$ and $R a b 11^{\mathrm{ex} 2}$ mutant tissues were generated in the eye using the eyFLP-FRT system [37]. To label Rab11 ex2 mutant clones, eyFLP; FRT82B, GMR-myr.GFP flies were crossed with FRT82B,

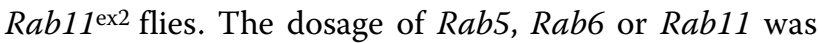
reduced by $50 \%$ in flies overexpressing RN-tre by crossing female flies $y w ;$ Cyo/UAS-RN-tre; long-GMR-GAL4I $T M 3, T b$ with male flies $w ; C y o / R a b 5^{2}, y w ; C y o / R a b 6^{\mathrm{D} 23 \mathrm{D}}$, or Rab11 ex2/TM3, $S b$, respectively. The full-length $R N$-tre cDNA (LD38355) was subcloned into the pUAST vector. The resulting construct was used to generate UAS-RNtre transgenic lines (BestGene Inc., CA).

\section{Histology and Immunohistochemistry}

Eye discs were dissected from third-instar larvae in ice cold phosphate-buffered saline (PBS, $\mathrm{pH}$ 7.0), and fixed in $2 \%$ paraformaldehyde in PBL $(0.075 \mathrm{M}$ lysine, $0.1 \mathrm{M}$ sodium phosphate buffer, $\mathrm{pH}$ 7.4) for 45 minutes at room temperature. Eye discs were washed three times in PBT (0.5\% Triton-X-100 in PBS) for 10 minutes, and then blocked in 10\% normal goat serum (NGS) in PBT for 1 hour at room temperature. Eye discs were subsequently incubated with primary antibody overnight at $4{ }^{\circ} \mathrm{C}$, washed three times in PBT for 10 minutes each, and then incubated with secondary antibody for 1 hour at room temperature. The discs were then washed three times in PBT, and once in PBS for 10 minutes each, and then incubated for 10 minutes in SlowFade Gold antifade reagent (Invitrogen) before mounting. Primary antibodies used are as follows: Chaoptin (24B10) (Developmental Studies Hybridoma Bank or DSHB, 1:200 dilution); Elav (DSHB, 1:500 dilution); Rab11 (provided by D.F.Ready, 1:1000 dilution); Cy2 AffiniPure Goat Anti-Horseradish Peroxidase (Jackson ImmunoResearch, 1:30 dilution). Secondary antibodies include antibodies from Jackson Immunochemicals: Texas-red-or FITC-conjugated goat anti-rabbit or anti-mouse antibodies (1:200 dilution); and antibodies from Molecular Probes: Alexa Fluor 488 goat anti-mouse and goat anti-rabbit IgG, Alexa Fluor 568 goat anti-rat and goat anti-rabbit IgG, and Alexa Fluor 647 goat anti-mouse IgG. All Alexa antibodies were used at 1:200 dilution. High-resolution fluorescence imaging system (Canberra Packard) was used to capture Z-series images, which were analyzed by 2D Deconvolution using the MetaMorph imaging software (Universal Imaging, Brandywine, PA). Longitudinal optic sectioning of eye discs was performed using confocal microscopy

Plastic sectioning of the eye disc stained with anti-Elav antibody was performed as described previously [25].

\section{EMS mutagenesis}

Homozygous GSd427 males aged 3-5 days were starved for 6 hours and fed with $2.5 \mathrm{mM}$ ethylmethanesulfonate (EMS) in 1\% sucrose overnight. The males were then crossed with females carrying GMR-GAL4 for 24 hours in fresh bottles, and were transferred to new bottles every 
12 hours for 4 days. The adult progeny (GSd427/GMRGAL4) were then collected and screened for the suppression of the reduced eye phenotype under dissection microscope. GSd427 mutant chromosomes showing suppression were balanced over $\mathrm{CyO}$.

Homozygous mutants for the GSV allele of GSd427 isolated from the screen were viable. The coding region of the $R N$-tre gene in homozygous GSV mutants was amplified by PCR and sequenced, which was compared to that in wild type and GSd427.

\section{Results}

A mis-localization phenotype induced by misexpression of genes in $\mathrm{R}$ cells

To search for genes required for R-cell development in the fly visual system, we crossed a collection of UAS-containing P-element insertion lines (i.e. GS lines) $[35,36]$ with the eye-specific GMR-GAL4 line to drive the expression of genes adjacent to the insertion site in $\mathrm{R}$ cells. Since GMR-GAL4 is expressed after cells exit the morphogenetic furrow, this allowed us to specifically assess the effect of gene misexpression on R-cell development after cells exit the furrow. R-cell nuclei were visualized using an antibody recognizing the neuronal-specific nuclear protein Elav.

We found that one P-element insertion GSd427 displayed a severe defect in R-cell positioning. In wild type (Figure 1A,C and 1E), after exiting the furrow, precursor cells differentiate sequentially into $\mathrm{R}$ cells, and $\mathrm{R}$-cell nuclei translocate from the basal region to the apical region, and maintain their apical localization throughout development. When gene/genes adjacent to the insertion GSd427 were misexpressed with GMR-GAL4, we found that although the initial translocation occurred normally as the nuclei of newly recruited $\mathrm{R}$ cells in the posterior region close to the furrow (i.e. within the distance of 6-7 rows of R-cell clusters) were able to translocate to the apical region, many of them failed to maintain their apical localization at later stage (i.e. $R$ cells located at more posterior region) and appeared at the basal region instead (Figure 1B,D and 1F).

RN-tre is the corresponding gene of the GSd427 misexpression phenotype GSd427 is inserted into a cytological region at $50 \mathrm{C} 23$ on the second chromosome. Molecular mapping data showed that GSd427 is inserted within the mastermind (mam) gene, $\sim 5.0 \mathrm{~kb}$ downstream of the transcription initiation site of $m a m$, and $\sim 5.5 \mathrm{~kb}$ upstream of the RN-tre gene (Figure 2A). Since the P-element insertion in GSd427 contains bidirectional UAS elements, it can potentially drive gene misexpression in the direction of mam or RN-tre.

To determine if mam or $R N$-tre was responsible for the GSd427 phenotype, we took the advantage of a P-element insertion called $U Y 333$ located at a site $\sim 588$ bp upstream

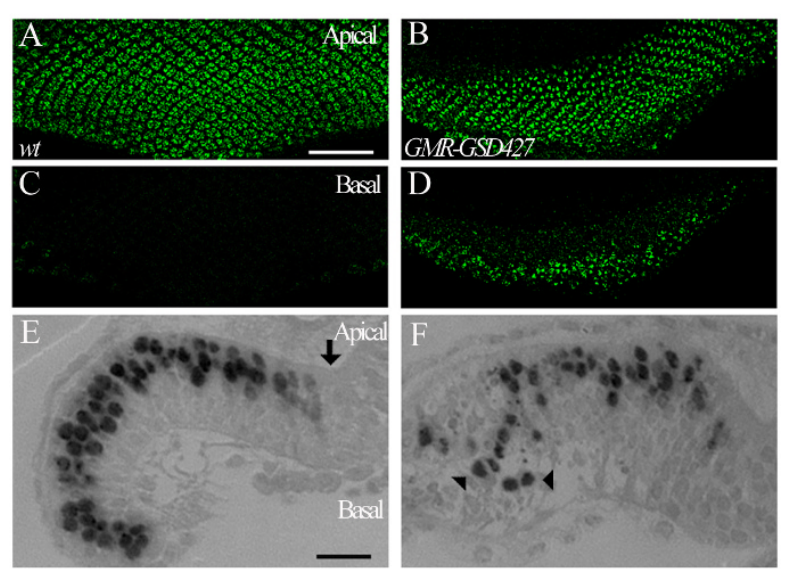

Figure 1 GSd427 driven by GMR-GAL4 caused defects in R-cell localization. (A-D) Apical ( $A$ and $B$ ) and basal ( $C$ and $D$ ) view of third-instar larval eye discs stained with anti-Elav. In wild type (A), R-cell bodies and nuclei are located at the apical region of the eye disc, and are absent at the basal region (C). The distance between the sections shown in $A$ and $C$ is $\sim 12 \mu \mathrm{m}$. In larvae carrying GSd427 under control of GMRGAL4 (B and D), many R-cell nuclei were mis-localized to the basal region (D). The distance between the sections shown in $B$ and $D$ is 13 $\mu \mathrm{m}$. (E and F) Longitudinal plastic sections of eye discs stained with anti-Elav (1 $\mu \mathrm{m}$ thick). Apical is up and basal is down. (E) In wild type, Rcell nuclei tanslocate to the apical region in the region posterior to the morphogenetic furrow (arrow). (F) In GSd427larvae, many R-cell nuclei (arrowheads) were mis-localized to the basal region ( $27.1 \%$ of ommatidia, $n=8$ eye discs). Note that the majority of R-cell nuclei were able to translocate to the apical region at earlier stage (i.e. R cells located close to the furrow). Scale bars: A-D, $50 \mu \mathrm{m} ; \mathrm{E}$ and F, $10 \mu \mathrm{m}$.

of the $R N$-tre transcriptional initiation site and $\sim 100 \mathrm{bp}$ downstream of the mam transcriptional initiation site (Figure 2A) [38]. Since $U Y 333$ contains a single UAS element, it can only drive gene misexpression in the direction of RN-tre. UY333 driven by GMR-GAL4 caused a Rcell mis-localization defect (Figure $2 \mathrm{C}$ and $2 \mathrm{E}$ ) that was indistinguishable from that in GSd427 misexpression mutants (Figure 1). This result suggests that the gene corresponding to the GSd427 gain-of-function phenotype is $R N$-tre, or other genes located at the $R N$-tre side of the insertion site.

To further determine the identity of the gene whose misexpression caused the R-cell mis-localization phenotype, we performed an EMS mutagenesis screen to isolate mutations on the GSd427-containing chromosome that suppress the GSd427 gain-of-function phenotype. We expected that some suppressor mutations would disrupt the function of the corresponding gene of the GSd427 misexpression phenotype. This approach has two advantages. First, it allows us to identify the corresponding gene. Second, it has the potential to generate strong lossof-function mutant alleles in that gene. Since GSd427 under control of GMR-GAL4 caused a severe adult rough eye phenotype, we were able to perform a large-scale genetic screen to isolate mutations on the GSd427-carry- 


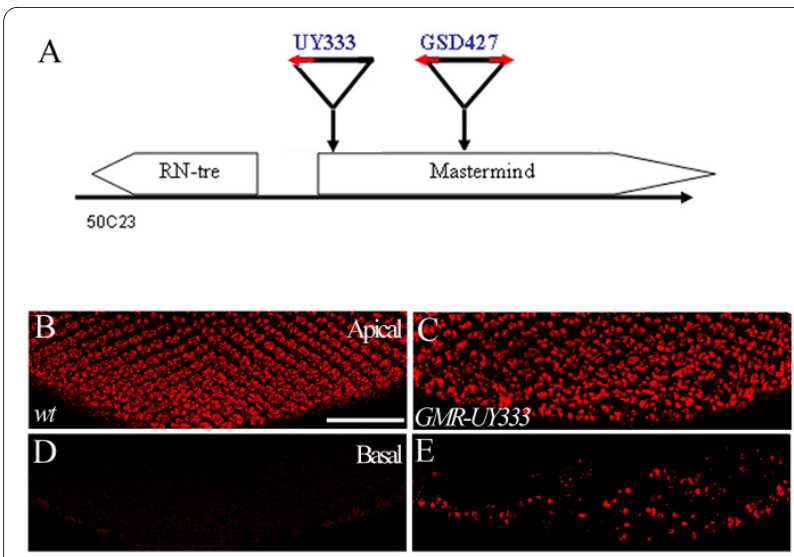

Figure 2 Uni-directional misexpression driven by the combination of UY333 and GMR-GAL4 caused R-cell defects identical to the GSd427 phenotype. (A) Relative positions of GSd427 and UY333 Pelement insertion sites in the genome. Both $P$ elements are inserted into the cytological region 50C23. GSd427 is inserted in a region $\sim 5.5$ $\mathrm{kb}$ upstream of RN-Tre and $\sim 5 \mathrm{~kb}$ downstream of the mam transcriptional initiation site, while UY333 is inserted into a site 588 base pairs upstream of RN-tre. GSd427 carries bi-directional UAS elements (red arrows) that can potentially drive gene transcription in both plus- and minus directions, while UY333 carries one UAS element that can drive gene expression only at the direction of RN-tre. (B-E) Apical (B and C) and basal ( $D$ and $E$ ) view of third-instar larval eye discs stained with anti-Elav antibody. (B and D) Apical (B) and basal (D) optic sections of wild-type eye discs. The distance between the sections shown in $B$ and $\mathrm{D}$ is $\sim 13 \mathrm{~mm}$. (C and E) Apical (C) and basal (E) optic sections of GMRGAL4-UY333 eye discs. Many R-cell nuclei were mis-localized to the basal region (E) ( $\sim 34 \%, n=1026$ ommatidia in 6 eye discs). The distance between the sections shown in $C$ and $E$ is $\sim 13 \mu \mathrm{m}$. Scale bar: B-E, 50 $\mu \mathrm{m}$.

ing chromosome that suppress the rough eye phenotype (Figure 3A). From 26,000 mutated GSd427-containing chromosomes, we established two lines with mutations that suppressed the rough eye phenotype associated with GSd427 misexpression. As predicted, both mutations also suppressed the GSd427 R-cell mis-positioning phenotype (data not shown). To determine the identity of the corresponding gene, we sequenced the mutant chromosome and identified a non-sense mutation (i.e. $R N-t r e$ GSV ) in the $R N$-tre gene that converts a codon for Trp287 into a stop codon. This mutation is predicted to generate a truncated protein missing part of the Rab-GAP domain and the complete $\mathrm{C}$-terminal regulatory region (Figure 3B).

While results from above analysis are consistent with that $R N$-tre is the corresponding gene whose overexpression caused the observed phenotype, it remains possible that haploinsufficiency of mam contributed to the phenotype as P element in both GSd427 and UY333 inserted into the mam gene. To further address this, we examined if misexpression of a $R N$-tre transgene in $\mathrm{R}$ cells is sufficient for inducing mis-localization phenotype. Indeed, we found that misexpression of $R N$-tre under control of
GMR-GAL4 caused a GSd427- and UY333-like mis-localization phenotype (Figure $3 \mathrm{D}$ ). We conclude that $R N$-tre is the gene whose misexpression caused the R-cell mislocalization phenotype.

\section{R-cell positioning occurs normally in RN-tre mutants}

To determine if RN-Tre is required for R-cell morphogenesis in the developing fly visual system, we performed loss-of-function analysis of the $R N$-tre mutants generated in our suppression screen. Third-instar larvae homozygous for the $R N-$ tre GSV $^{\mathrm{GS}}$ allele were examined for potential defects in R-cell nuclear translocation. However, no defect was observed (Figure 4). Thus, it remains unclear if endogenous RN-Tre plays a role in R-cell morphogenesis during development.

\section{RN-Tre interacts with Rab5 and Rab11 in the eye}

Since mammalian RN-Tre has been shown to possess GAP activity and negatively regulate the activity of certain Rabs in cultured cells $[32,33,39]$, we speculated that the $R N$-tre misexpression phenotype reflects a requirement for Rab-mediated vesicular transport in R-cell positioning during development. To assess this, we examined the potential genetic interaction between RN-Tre and several Rab family proteins. We used the long GMR-GAL4 driver to overexpress UAS-RN-tre in the fly eye. This eyespecific driver is more specific to photoreceptor cell than the regular GMR-GAL4 driver [40](see previous section). Overexpression of UAS-RN-tre under control of the longGMR-GAL4 driver caused a rough eye phenotype that is much milder than that induced by GMR-GAL4 (Compare Figure $5 \mathrm{~A}$ to Figure $3 \mathrm{~A} ; 100 \%, \mathrm{n}>30$ eyes). We reasoned that if this rough eye phenotype is due to the negative regulation of the activity of some Rab proteins by overexpression of $R N$-tre, reducing the dosage of such Rab proteins would enhance the rough eye phenotype. To test this, we examined the effect of reducing the dosage of $R a b 5, R a b 6$ or $R a b 11$ by $50 \%$ on the $R N$-tre-induced eye phenotype. We found that reducing the dosage of Rab5 $(52 \%, n=76$ eyes, Figure 5B) or Rab11 (90\%, n = 20 eyes, Figure 5D) significantly enhanced the $R N$-tre-induced rough eye phenotype, whereas no such enhancement was observed when the dosage of Rab6 was reduced $(0 \%, \mathrm{n}=$ 24 eyes, Figure $5 \mathrm{C}$ ). This result suggests that overexpression of $\mathrm{RN}$-tre negatively regulates the activity of Rab5 and Rab11 in the fly eye.

\section{Rab5 is required for apical localization of $R$-cell nuclei}

Rab5 is a key regulator of protein internalization, early endocytic vesicular transport and the fusion of endocytic vesicles with early endosomes [41,42]. To address the possibility that the RN-Tre misexpression phenotype reflects an active role for Rab5 in the control of R-cell apical localization, we performed loss-of-function analysis 
A

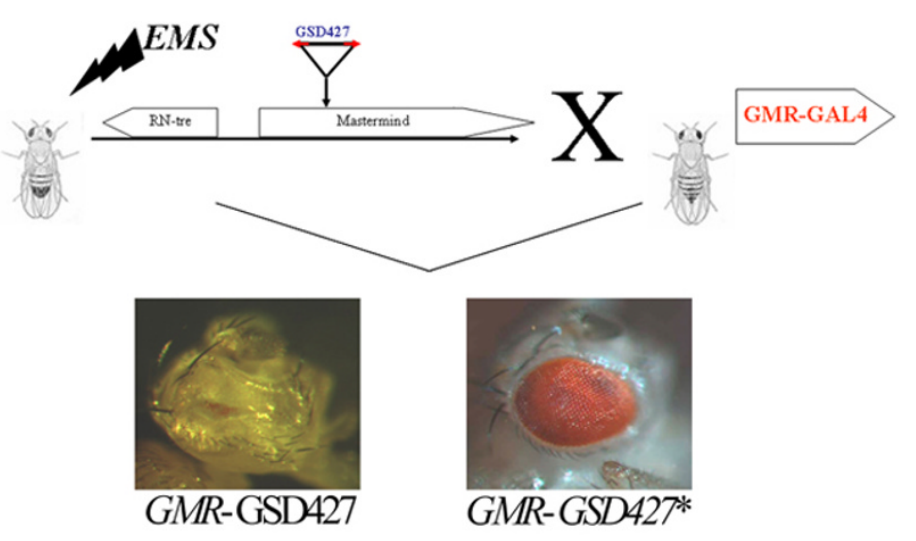

$\mathrm{B}$
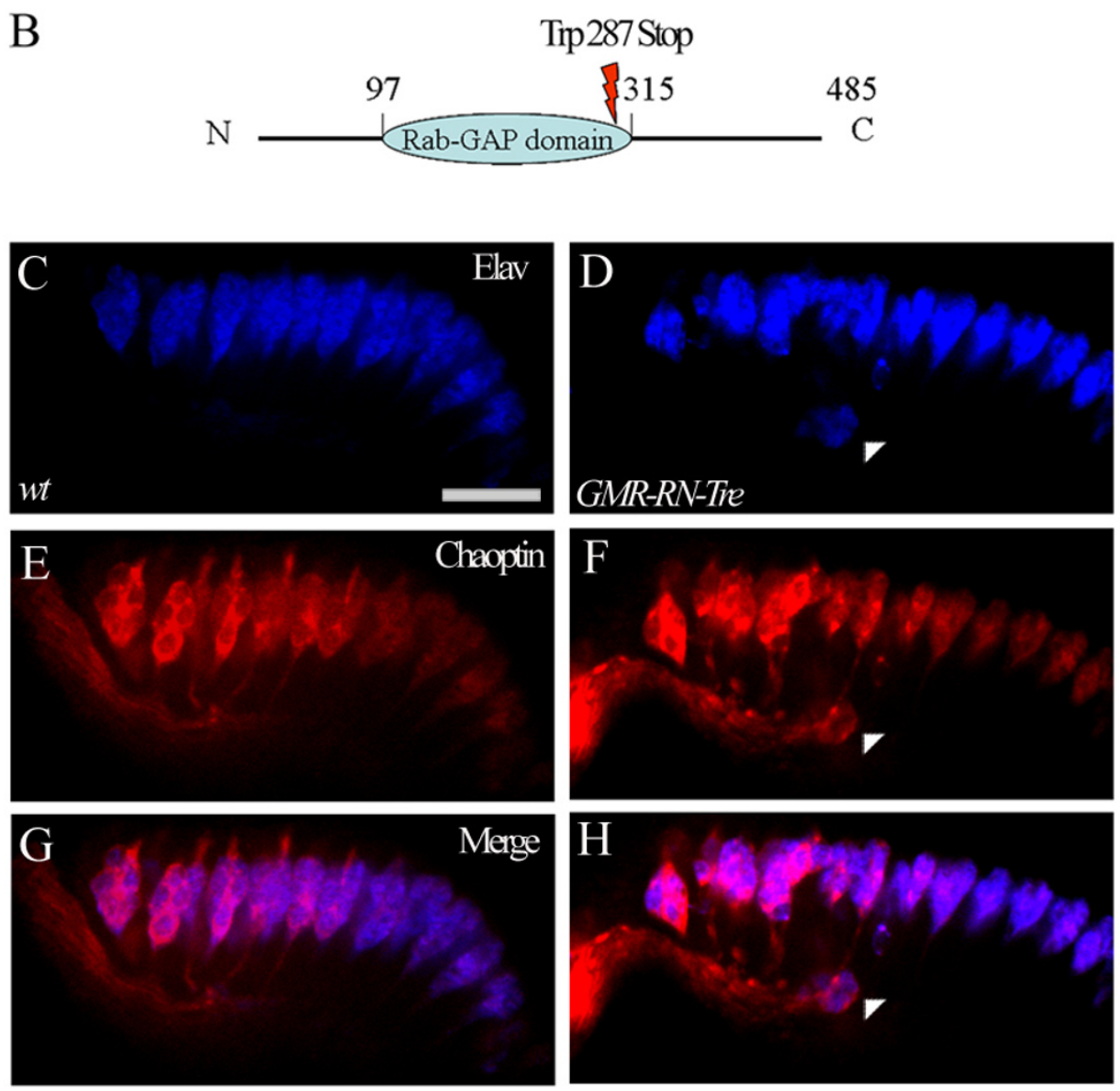

Figure $3 \mathrm{RN}$-tre is the corresponding gene of the GSd427 and UY333 misexpression phenotype. (A) An EMS mutagenesis screen for identifying the suppressors of the GSd427 gain-of-function eye phenotype. Males carrying the GSd427-containing chromosome were mutagenized by EMS ingestion and then crossed with females carrying GMR-GAL4. The F1 progeny were screened for the suppression of the reduced eye phenotype. (B) Sequencing of the $R N$-tre gene in one suppressor (GSV) allele reveals a non-sense point mutation at nucleotide 1119 that converts the codon for Trp into a stop codon at amino-acid 287. (C-H) Longitudinal optic sectioning of third-instar eye discs double-stained with anti-Elav (blue) and MAb $24 \mathrm{~B} 10$ (Chaoptin) (red) antibodies to visualize R-cell nuclei and R-cell surface, respectively. (C, E and G) Wild-type eye discs show apical localization of R cells. (D, F and H) Misexpression of UAS-RN-tre under control of GMR-GAL4 induced basal localization of R cells $(D, F, H$, arrowheads) $(\sim 32 \%, n=1008$ ommatidia in 6 eye discs). Scale bar: $10 \mu \mathrm{m}$. 


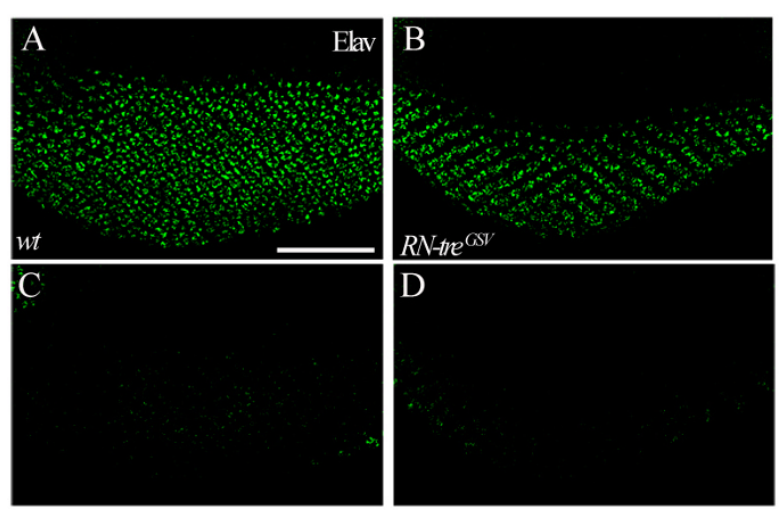

Figure 4 Loss of $\boldsymbol{R} \boldsymbol{N}$-tre did not affect R-cell nuclear positioning (A-D) Apical ( $A$ and B) and basal (C and D) view of third-instar larval eye discs stained with anti-Elav. (A and C) Wild type. The distance between the sections shown in $A$ and $C$ is $\sim 16 \mu \mathrm{m}$. (B and D) In RN-Tre ${ }^{G S V}$ mutants, R-cell nuclei appeared normally in the apical region (B) and were not found in the basal region (D) $(n=13$ eye discs). The distance between the sections shown in B and D is $\sim 16 \mu \mathrm{m}$. Scale bar: $50 \mu \mathrm{m}$.

to determine if mutations in Rab5 affect R-cell nuclear positioning. Large patches of mutant clones homozygous for a $R a b 5$ null allele (i.e.Rab52) were generated in the eye using eyFLP/FRT-based mitotic recombination [37]. However, we were unable to analyze R-cell positioning in homozygous null tissues as complete loss of Rab5 prevented R-cell differentiation and led to the overgrowth of eye-imaginal discs (data not shown), which is consistent with the previous observation by Bilder and colleagues [43].

To circumvent this problem, we took an alternative approach. A dominant-negative form of Rab5 (Rab5S43N) was expressed in the posterior region of the third-instar larval eye disc under control of GMR-GAL4. Eye discs expressing this Rab5S43N displayed normal morphology, and differentiating $\mathrm{R}$ cells in the eye disc also expressed normal R-cell developmental markers (Figure 6E,F and 6H). However, we found that many Rcell nuclei failed to maintain their apical localization (Figure 6E) and instead mis-localized basally (Figure 6F and $6 \mathrm{H})$. By contrast, loss of Rab6, a key regulator of ER-toGolgi vesicular trafficking $[44,45]$, has no effect on R-cell nuclear positioning (Figure 6C and 6D).

\section{Shibire/dynamin is also required for R-cell apical localization}

Above results suggest that the Rab5-mediated early endocytic pathway is required for R-cell apical localization. If so, one may predict that mutations in other genes involved in early endocytic trafficking should also affect R-cell positioning. To address this possibility, we tested whether loss of Shibire (Shi), the fly homolog of dynamin that is another key regulator of endocytosis, affects R-cell nuclear localization.
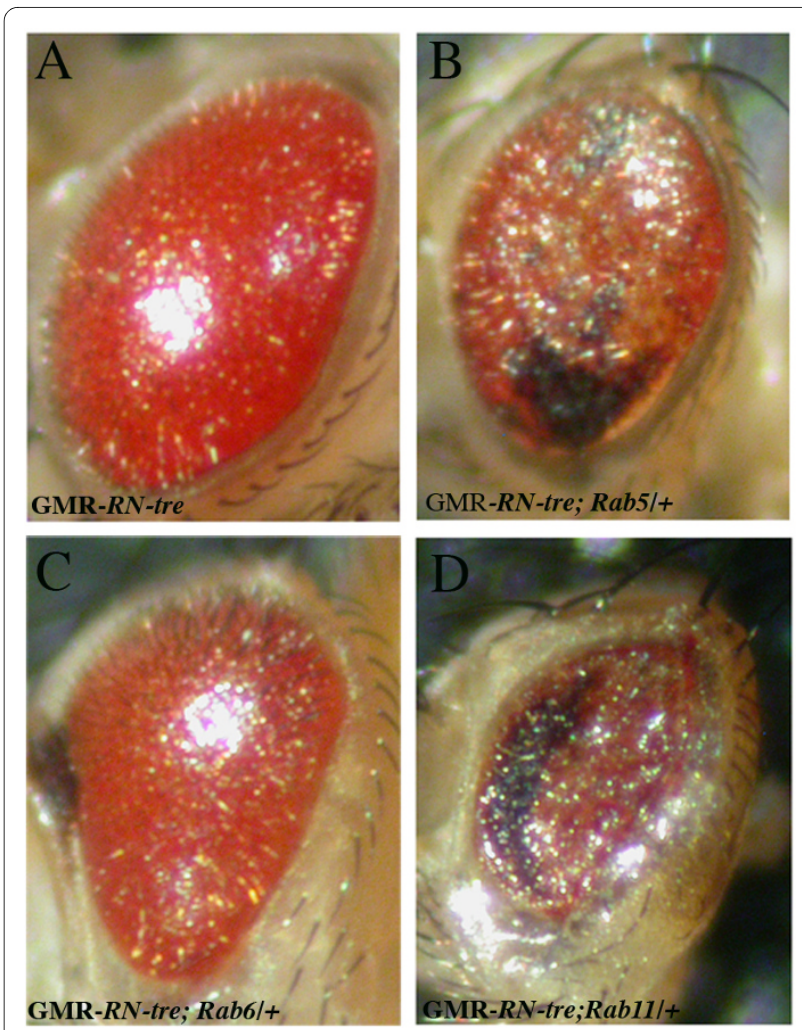

Figure 5 Rab5 and $R a b 11$ mutations enhanced the $R N$-tre overexpression eye phenotype. (A) Ovexpression of $R N$-tre under control of the longGMR-GAL4 driver caused a mild rough eye phenotype. The eye appeared glassy and smooth. Genotype: UAS-RN-tre/+; longGMRGAL4/+. (B) Reducing the dosage of Rab5 by $50 \%$ enhanced the $R N$-tre overexpression eye phenotype. The eye became flat and displayed a necrotic phenotype. Genotype: UAS-RN-tre/Rab52; longGMR-GAL4/+ (C) Reducing the dosage of Rab6 did not enhance the $R N$-tre overex-

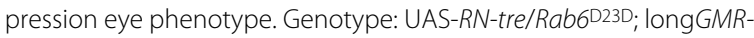
GAL4/+. (D) Reducing the dosage of Rab11 also significantly enhanced the RN-tre overexpression eye phenotype. Genotype: UAS-RN-tre/+; longGMR-GAL4/Rab11 ex2.

We used a temperature-sensitive, dominant-negative form of shi (UAS-shits1) to examine the effect of reducing the activity of Shi on R-cell positioning. It has been shown previously that at the restrictive temperature (i.e. $32^{\circ} \mathrm{C}$ ) shits1 could completely block endocytosis (e.g. $[46,47])$. We used $G M R-G A L 4$ to express UAS- $s h i^{\text {ts1 }}$ specifically in the posterior region of the third-instar larval eye disc. R-cell localization appeared normal at permissive temperature (i.e. $18^{\circ} \mathrm{C}$ ) (data not shown). In contrast, when larvae were reared at restrictive temperature, they displayed a severe R-cell nuclear mis-localization phenotype (Figure 6I) that was indistinguishable from that in larvae expressing the dominant-negative form of Rab5S43N (Figure 6H). Together, these results point to a key role for the early endocytic pathway in maintaining apical localization of $\mathrm{R}$ - cell nuclei in the developing eye disc. 

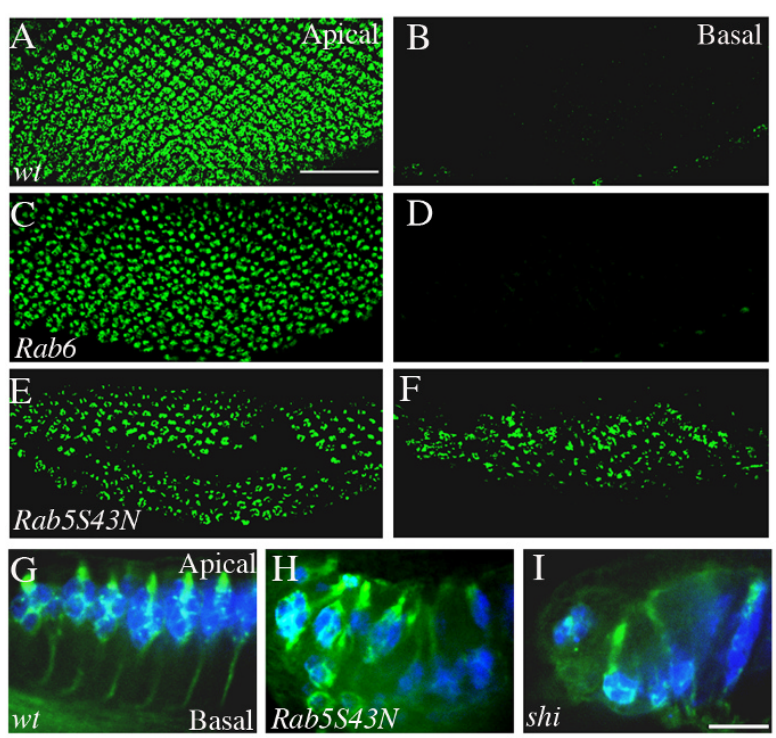

Figure 6 Rab5 and Shi are required for apical localization of R-cell nuclei in the eye disc. (A-F) Apical (,$C$ and $E$ ) and basal (B, D and F) view of third-instar larval eye discs stained with anti-Elav antibody. The distance between apical and basal sections is $\sim 15 \mu \mathrm{m}$. (A and B) In wild type, R-cell nuclei are localized to the apical region (A) and thus are not present in the basal region (B). (C and D) In a Rab6 null (Rab6D23D) mutant eye disc, R-cell nuclei appeared normally at the apical region (C). (E and F) In an eye disc expressing the dominant-negative form of Rab5 (Rab5S43N), many R-cell nuclei were missing in the apical region (E) and mis-localized to the basal region (F). (G-I) Longitudinal optic sectioning of third-instar eye discs double-stained with anti-Elav (blue) and anti-HRP (green) to visualize R-cell nuclei and R-cell surface, respectively. (G) Wild type. $(\mathrm{H})$ In eye discs expressing Rab5S43N, 27\% ommatidia contained mis-localized R-cell nuclei ( $n=5$ eye discs). (I) Eye discs expressing the dominant-negative form of shi (i.e. shits 1 ) displayed a R-cell mis-localization phenotype ( $34 \%$ ommatidia, $n=7$ eye discs). Scale bars: A-F, $50 \mu \mathrm{m} ; \mathrm{G}-\mathrm{I}, 10 \mu \mathrm{m}$.

\section{Rab11-mediated recycling is also required for $\mathrm{R}$-cell positioning}

One possible explanation for the Rab5- and Shi mis-localization phenotype is that endocytosis of certain membrane proteins maintains the apical localization of R-cell nuclei during development. Alternatively or additionally, Rab5- and Shi-mediated endocytosis may be necessary for retargeting these membrane proteins to specific subcellular locations by a Rab-regulated vesicular recycling pathway. The latter hypothesis is supported by that reducing the dosage of Rab11 also significantly enhanced the $R N$-tre-induced rough eye phenotype (see Figure 5). To further address this, we tested if loss of Rab11, an evolutionarily conserved key regulator of vesicular recycling $[48,49]$, affected R-cell positioning.

Tissues homozygous for a strong Rab11 loss-of-function allele $R a b 11^{\mathrm{ex} 2}$ were generated in the eye using eyFLP/FRT-induced mitotic recombination [37]. While mutant R-cell clusters still projected processes that attached to the apical surface and correctly sent axons basally, we found that many R-cell nuclei appeared abnormally at the basal side (Figure 7B and 7D).

We also examined if silencing Rab11 by RNA interference (RNAi) approach caused a similar R-cell mis-localization phenotype. We expressed a UAS-Rab11-RNAi transgene specifically in the eye, which has been shown previously to significantly reduce the level of Rab11 in $R$ cells [50]. Indeed, we found that reducing the level of Rab11 with RNAi also caused a failure for R-cell nuclei to maintain their apical localization (Figure 7C). Instead of forming a tightly associated R-cell cluster in the apical region, as is observed in wild type (Figure 7A), R-cell clusters in Rab11 RNAi individuals extended in a long stretch with the distribution of R-cell nuclei along the entire apical-basal axis (Figure 7C).

That loss of Rab11 caused a Rab5- and Shi-like R-cell mis-localization phenotype suggests that Rab5, Shi and Rab11 function together in vesicular transport to maintain apical localization of $\mathrm{R}$ cells during development.

\section{Discussion}

The movement of R-cell nuclei along the apical-basal axis in the developing fly visual system displays features very similar to the somal translocation of neurons from the ventricular zone to the cortical plate during the development of the mammalian cerebral cortex [51,52]. That both R-cell movement and cortical neuronal migration require the function of DLis/Lis1 [14,18] support the evolutionary conservation of the molecular mechanism controlling neuronal positioning. In a search for novel regulators of $\mathrm{R}$-cell translocation, we found that misexpression of the RabGAP RN-Tre caused a failure for Rcell nuclei to maintain their apical localization, suggesting the requirement of Rab-mediated vesicular transport in R-cell positioning. RN-tre displayed dosage-sensitive interactions with $R a b 5$ or $R a b 11$ in the fly eye, and genetic analysis revealed an essential role for Rab5, Shi and Rab11 in R-cell apical localization. These results support that Rab5, Shi and Rab11 function together in a vesicular transport pathway to regulate R-cell positioning during development.

RN-Tre, like most of RabGAPs, contains a Tre2/Bub2/ Cdc16 (TBC) domain that accelerates the GTPase activity of Rabs with an Arg-Glu dual-finger mechanism [53]. Mammalian RN-Tre was originally identified by Di Fiore and colleagues as a binding partner of Eps8, a substrate of the epidermal growth factor receptor (EGFR) [54]. Subsequent studies by the same group show that RN-tre specifically accelerates GTP hydrolysis by Rab5 in vitro [32]. Consistently, overexpression of RN-Tre in cultured cells was shown to block Rab-5-dependent EGFR internalization [32]. Mammalian RN-tre was also reported to possess GAP activity towards Rab41 [33] and Rab43 [39]. That reducing the dosage of Rab5 or Rab11 enhanced the 

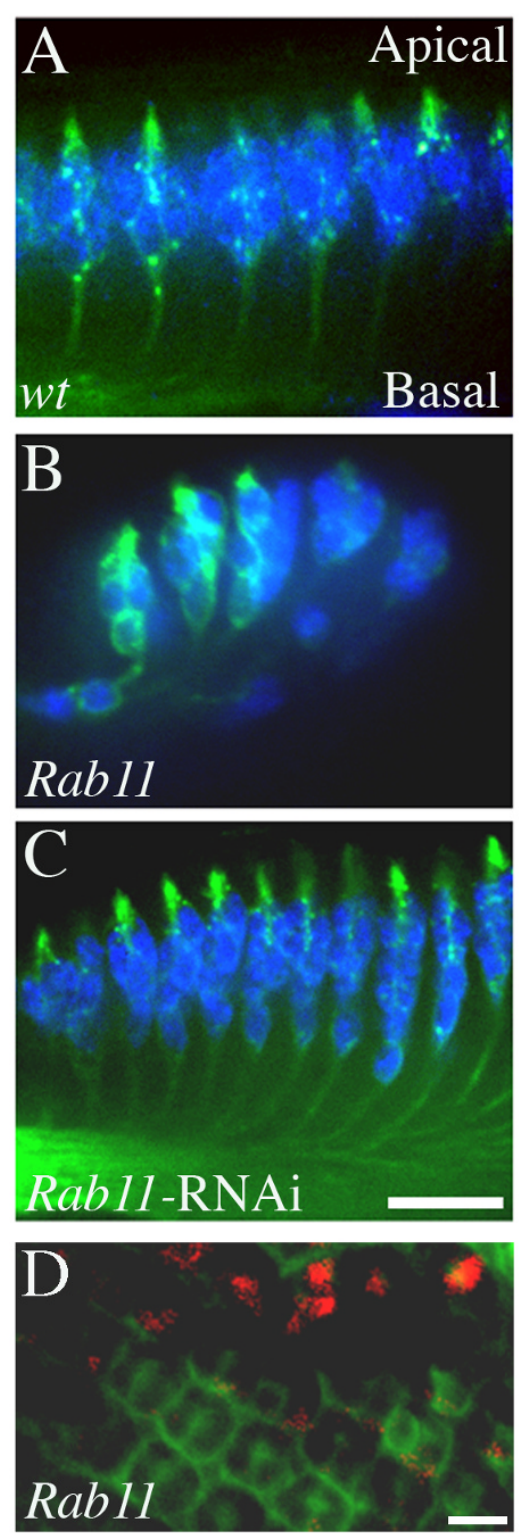

Figure 7 Rab1 1 is also required for R-cell positioning. (A-C) Longitudal optic sectioning of third-instar larval eye discs double-stained with anti-Elav (blue) and anti-HRP (green) to visualize R-cell nuclei and R-cell surface, respectively. (A) In wild type, R-cell bodies localizes to the apical region, while their apical processes attach to the apical surface and their axons project basally. (B) The generation of clones of Rab1 1 ex2 mutant cells caused R-cell nuclei to be mis-localized at the basal region. (C) In eye discs expressing a UAS-Rab 11-RNAi transgene, $R$ cells did not appear to be tightly associated clusters at the apical region and instead formed a long stretch along the apical-basal axis (20 out of 41 eye discs examined). Note that R-cell processes still attached to the apical surface in Rab11 mutants (B and C). (D) Basal localization of Rab11 mutant nuclei in Rab1 1 ex2 mosaic eye disc. GFP (green) was used to label wild-type or Rab11 heterozygous ommatidia in Rab11 mosaic eyes. R-cell nuclei at the basal region were visualized with antiElav staining (red). In GFP-positive ommatidia, no R-cell nuclei were observed in the basal region. In the basal region of homozygous Rab11 mutant ommatidia or mosaic ommatida (GFP negative), mis-localized R-cell nuclei (red) were observed. Scale bar: A-C,10 $\mu \mathrm{m} ; \mathrm{D}, 5 \mu \mathrm{m}$.
RN-tre-overexpression eye phenotype (Figure 4), together with that loss of Rab5 or Rab11 caused a R-cell mis-localization phenotype (Figure 5 and 6) identical to that in flies misexpressing RN-Tre (Figure 1, 2, 3), suggests that Rab5 and Rab11 are targets of RN-Tre in Drosophila.

While the results from misexpression of RN-Tre provided an entry point for genetic dissection of the role of Rab-mediated vesicular transport in R-cell positioning, the in vivo role of RN-Tre remains unknown. Our genetic analysis of available $R N$-tre loss-of-function alleles failed to reveal a defect in $\mathrm{R}$-cell nuclear translocation. There are two possible explanations for the lack of R-cell phenotype in RN-tre mutants. First, other RabGAPs may be functionally redundant with RN-Tre and thus compensate for loss of RN-Tre. And second, while Rab-mediated vesicular transport is necessary for maintaining R-cell nuclear positioning, elevated activity of Rabs in RN-tre mutants is not sufficient to cause a translocation phenotype. Our current data does not allow us to distinguish among these possibilities.

Rab5, Shi/dynamin and Rab11 have been implicated in regulating vesicular transport in a variety of cellular processes in both vertebrates and invertebrates [41,42,5557]. Rab5 is required for protein internalization [58], the transport of early endocytic vesicles and their subsequent fusion to the early endosome [59]. Shi/dynamin is also required for the internalization process during the early endocytic pathway (e.g.[57,60,61]). In addition, Shi is required for vesicle recycling and budding during exocytosis [62,63]. Rab11 has been shown to be involved in regulating both endosome recycling (e.g.[48,64,65]) and post-Golgi trafficking of newly synthesized membrane proteins [50]. That loss of Rab5, Shi and Rab11, but not Rab6, caused a similar R-cell mis-localization phenotype suggests strongly that they are involved in a common vesicular transport pathway for maintaining $\mathrm{R}$-cell apical localization during development.

How do Rab5, Shi/dynamin and Rab11 function together to maintain apical localization of R-cell nuclei? One attractive model is that Rab5, Shi/dynamin and Rab11 are involved in a common endocytic-recycling pathway for targeting specific proteins to regulate R-cell positioning. The requirement of the Rab-mediated endocytic-recycling pathway in cell migration has attracted much attention in recent years [66]. For instance, it has been shown that the migration of border cells during Drosophila oogenesis requires the endocytosis and subsequent recycling of cell surface receptor tyrosine kinases (RTK) to maintain the polarized localization of RTK signaling at the leading edge [67]. Mammalian cell culture studies also show that the endocytic-recycling pathway is required for maintaining the polarized localization of integrins at the leading edge to control cell migration (e.g. 
[68-70]). Recent studies also show that Rab-mediated trafficking of E-cadherin plays an important role in regulating cell intercalation [71] and cell polarity during development [72]. Similarly, we speculate that Rab5-ShiRab11 may function in R cells to regulate the polarization of specific cell surface proteins, which in turn modulate actin- and microtubule-based cytoskeleton for maintaining apical localization of R-cell nuclei. Such mechanism may also be utilized in mammals to regulate neuronal positioning during brain development. Thus, it will be of interest to determine if the Rab-mediated endocyticrecycling pathway is also required for establishment of tissue architecture in mammalian cerebral cortex, and if this pathway regulates the specific localization of receptor proteins such as APOER2, VLDLR or integrins that have been implicated in mediating cortical neuronal migration in mammals (e.g. [73-76]).

\section{Conclusion}

Mis-regulation of the RabGAP RN-Tre is sufficient to cause a failure of R-cell nuclei to maintain their apical localization in the developing Drosophila eye. That RNTre interacts genetically with Rab5 and Rab11 suggests that Rab5 and Rab11 are targets of RN-Tre in Drosophila. Rab-mediated vesicular transport involving Rab5, Shi/ dynamin and Rab11 plays an essential role in maintaining R-cell apical localization in the developing fly eye.

\section{Competing interests}

The authors declare that they have no competing interests.

\section{Authors' contributions}

$\mathrm{TH}$ conducted most of experiments, and was involved in writing the manuscript. DvM generated the GSd427 line. LS conducted genetic interaction experiments. YR supervised and wrote the manuscript. All authors read and approve the manuscript.

\section{Acknowledgements}

We thank the Bloomington Stock Center, D. Bilder, M. Gonzalez-Gaitan, Y. Zhong, R. S. Cohen, A. Guichet, D. F. Ready and J. A. Knoblich for fly stocks; the Drosophila Genomic Resource Center (DGRC) for the LD38555 cDNA clone. This work was supported by an operating grant (MOP-14688) awarded to Yong Rao from Canadian Institutes of Health Research. Yong Rao is a Le Fonds de la Recherche en Sante' de Que'bec senior research scholar.

\section{Author Details}

McGill Centre for Research in Neuroscience, Department of Neurology and Neurosurgery, Department of Medicine, McGill University Health Centre, 1650 Cedar Avenue, Montreal, Quebec H3G 1A4, Canada

Received: 16 February 2010 Accepted: 11 June 2010

Published: 11 June 2010

\section{References}

1. Hatten ME: New directions in neuronal migration. Science 2002, 297:1660-1663.

2. Kriegstein AR, Noctor SC: Patterns of neuronal migration in the embryonic cortex. Trends Neurosci 2004, 27:392-399.

3. Marin O, Rubenstein JL: Cell migration in the forebrain. Annu Rev Neurosci 2003, 26:441-483.

4. Kriegstein A, Noctor S, Martinez-Cerdeno V: Patterns of neural stem and progenitor cell division may underlie evolutionary cortical expansion. Nat Rev Neurosci 2006, 7:883-890.
5. Edmondson JC, Hatten ME: Glial-guided granule neuron migration in vitro: a high-resolution time-lapse video microscopic study. J Neurosci 1987, 7:1928-1934.

6. de Curtis I: Cell migration: GAPs between membrane traffic and the cytoskeleton. EMBO Rep 2001, 2:277-281.

7. Ridley AJ: Rho GTPases and cell migration. J Cell Sci 2001, 114:2713-2722.

8. Morris NR, Efimov VP, Xiang X: Nuclear migration, nucleokinesis and lissencephaly. Trends Cell Biol 1998, 8:467-470.

9. Lambert de Rouvroit CG, offinet AM: Neuronal migration. Mech Dev 2001, 105:47-56.

10. Ayala R, Shu T, Tsai LH: Trekking across the brain: the journey of neuronal migration. Cell 2007, 128:29-43.

11. Tsai LH, Gleeson JG: Nucleokinesis in neuronal migration. Neuron 2005, 46:383-388.

12. Vallee RB, Tsai JW: The cellular roles of the lissencephaly gene LIS1, and what they tell us about brain development. Genes Dev 2006, 20:1384-1393.

13. Stewart RM, Richman DP, Caviness VS Jr: Lissencephaly and Pachygyria: an architectonic and topographical analysis. Acta Neuropathol (Berl) 1975, 31:1-12

14. Reiner O, Carrozzo R, Shen Y, Wehnert M, Faustinella F, Dobyns WB, Caskey $\mathrm{CT}$, Ledbetter DH: Isolation of a Miller-Dieker lissencephaly gene containing $\mathrm{G}$ protein beta-subunit-like repeats. Nature 1993, 364:717-721.

15. Lo Nigro C, Chong CS, Smith AC, Dobyns WB, Carrozzo R, Ledbetter DH: Point mutations and an intragenic deletion in LIS1, the lissencephaly causative gene in isolated lissencephaly sequence and Miller-Dieker syndrome. Hum Mol Genet 1997, 6:157-164.

16. Xiang X, Osmani AH, Osmani SA, Xin M, Morris NR: NudF, a nuclear migration gene in Aspergillus nidulans, is similar to the human LIS-1 gene required for neuronal migration. Mol Biol Cell 1995, 6:297-310.

17. Liu Z, Xie T, Steward R: Lis1, the Drosophila homolog of a human lissencephaly disease gene, is required for germline cell division and oocyte differentiation. Development 1999, 126:4477-4488.

18. Swan A, Nguyen T, Suter B: Drosophila Lissencephaly-1 functions with Bic-D and dynein in oocyte determination and nuclear positioning. Nat Cell Biol 1999, 1:444-449.

19. Sapir T, Elbaum M, Reiner O: Reduction of microtubule catastrophe events by LIS1, platelet-activating factor acetylhydrolase subunit. Embo J 1997, 16:6977-6984.

20. Feng Y, Olson EC, Stukenberg PT, Flanagan LA, Kirschner MW, Walsh CA LIS1 regulates CNS lamination by interacting with $\mathrm{mNudE}$, a central component of the centrosome. Neuron 2000, 28:665-679.

21. Morris SM, Albrecht U, Reiner O, Eichele G, Yu-Lee LY: The lissencephaly gene product Lis1, a protein involved in neuronal migration, interacts with a nuclear movement protein, NudC. Curr Biol 1998, 8:603-606.

22. Sasaki S, Shionoya A, Ishida M, Gambello MJ, Yingling J, Wynshaw-Boris A, Hirotsune S: A LIS1/NUDEL/cytoplasmic dynein heavy chain complex in the developing and adult nervous system. Neuron 2000, 28:681-696.

23. Niethammer M, Smith DS, Ayala R, Peng J, Ko J, Lee MS, Morabito M, Tsai LH: NUDEL is a novel Cdk5 substrate that associates with LIS1 and cytoplasmic dynein. Neuron 2000, 28:697-711.

24. Mosley-Bishop KL, Li Q, Patterson L, Fischer JA: Molecular analysis of the klarsicht gene and its role in nuclear migration within differentiating cells of the Drosophila eye. Curr Biol 1999, 9:1211-1220.

25. Houalla T, Hien Vuong D, Ruan W, Suter B, Rao Y: The Ste20-like kinase misshapen functions together with Bicaudal-D and dynein in driving nuclear migration in the developing drosophila eye. Mech Dev 2005, 122:97-108

26. Kracklauer MP, Banks SML, Xie X, Wu Y, Fischer JA: Drosophila Klaroid encodes a SUN domain protein required for Klarsicht localization to the nuclear envelope and nuclear migration in the eye. Fly 2007, 1:75-85.

27. Tomlinson A: The cellular dynamics of pattern formation in the eye of Drosophila. J Embryol Exp Morphol 1985, 89:313-331.

28. Fan SS, Ready DF: Glued participates in distinct microtubule-based activities in Drosophila eye development. Development 1997 124:1497-1507.

29. Whited JL, Cassell A, Brouillette M, Garrity PA: Dynactin is required to maintain nuclear position within postmitotic Drosophila photoreceptor neurons. Development 2004, 131:4677-4686. 
30. Welte MA, Gross SP, Postner M, Block SM, Wieschaus EF: Developmental regulation of vesicle transport in Drosophila embryos: forces and kinetics. Cell 1998, 92:547-557.

31. Patterson K, Molofsky AB, Robinson C, Acosta S, Cater C, Fischer JA: The functions of Klarsicht and nuclear lamin in developmentally regulated nuclear migrations of photoreceptor cells in the Drosophila eye. $\mathrm{Mol}$ Biol Cell 2004, 15:600-610.

32. Lanzetti L, Rybin V, Malabarba MG, Christoforidis S, Scita G, Zerial M, Di Fiore PP: The Eps8 protein coordinates EGF receptor signalling through Rac and trafficking through Rab5. Nature 2000, 408:374-377.

33. Haas AK, Fuchs E, Kopajtich R, Barr FA: A GTPase-activating protein controls Rab5 function in endocytic trafficking. Nat Cell Biol 2005, 7:887-893.

34. Deneka $M$, Neeft $M$, van der Sluijs $P$ : Regulation of membrane transport by rab GTPases. Crit Rev Biochem Mol Bio/ 2003, 38:121-142.

35. Toba G, Ohsako T, Miyata N, Ohtsuka T, Seong KH, Aigaki T: The gene search system. A method for efficient detection and rapid molecular identification of genes in Drosophila melanogaster. Genetics 1999, 151:725-737.

36. Mindorff EN, O'Keefe DD, Labbe A, Yang JP, Ou Y, Yoshikawa S, van Meyel $D J:$ A gain-of-function screen for genes that influence axon guidance identifies the NF-kappaB protein dorsal and reveals a requirement for the kinase Pelle in Drosophila photoreceptor axon targeting. Genetics 2007, 176:2247-2263.

37. Newsome TP, Asling B, Dickson BJ: Analysis of Drosophila photoreceptor axon guidance in eye-specific mosaics. Development 2000, 127:851-860

38. Nicolai M, Lasbleiz C, Dura JM: Gain-of-function screen identifies a role of the Src64 oncogene in Drosophila mushroom body development. J Neurobiol 2003, 57:291-302.

39. Fuchs E, Haas AK, Spooner RA, Yoshimura S, Lord JM, Barr FA: Specific Rab GTPase-activating proteins define the Shiga toxin and epidermal growth factor uptake pathways. J Cell Biol 2007, 177:1133-1143.

40. Wernet MF, Labhart T, Baumann F, Mazzoni EO, Pichaud F, Desplan C: Homothorax switches function of Drosophila photoreceptors from color to polarized light sensors. Cell 2003, 115:267-279.

41. Simpson JC, Jones AT: Early endocytic Rabs: functional prediction to functional characterization. Biochem Soc Symp 2005:99-108.

42. Somsel Rodman J, Wandinger-Ness A: Rab GTPases coordinate endocytosis. J Cell Sci 2000, 113(Pt 2):183-192.

43. Lu H, Bilder D: Endocytic control of epithelial polarity and proliferation in Drosophila. Nat Cell Biol 2005, 7:1232-1239.

44. Coutelis JB, Ephrussi A: Rab6 mediates membrane organization and determinant localization during Drosophila oogenesis. Development 2007, 134:1419-1430

45. Januschke J, Nicolas E, Compagnon J, Formstecher E, Goud B, Guichet A: Rab6 and the secretory pathway affect oocyte polarity in Drosophila. Development 2007, 134:3419-3425.

46. Kitamoto T: Conditional modification of behavior in Drosophila by targeted expression of a temperature-sensitive shibire allele in defined neurons. J Neurobio/ 2001, 47:81-92.

47. Entchev EV, Schwabedissen A, Gonzalez-Gaitan M: Gradient formation of the TGF-beta homolog Dpp. Cell 2000, 103:981-991.

48. Ullrich O, Reinsch S, Urbe S, Zerial M, Parton RG: Rab11 regulates recycling through the pericentriolar recycling endosome. J Cell Biol 1996, 135:913-924.

49. Dollar G, Struckhoff E, Michaud J, Cohen RS: Rab11 polarization of the Drosophila oocyte: a novel link between membrane trafficking, microtubule organization, and oskar mRNA localization and translation. Development 2002, 129:517-526.

50. Satoh AK, O'Tousa JE, Ozaki K, Ready DF: Rab11 mediates post-Golgi trafficking of rhodopsin to the photosensitive apical membrane of Drosophila photoreceptors. Development 2005, 132:1487-1497.

51. Nadarajah B, Brunstrom JE, Grutzendler J, Wong RO, Pearlman AL: Two modes of radial migration in early development of the cerebral cortex. Nat Neurosci 2001, 4:143-150.

52. Nadarajah B, Parnavelas JG: Modes of neuronal migration in the developing cerebral cortex. Nat Rev Neurosci 2002, 3:423-432.

53. Pan X, Eathiraj S, Munson M, Lambright DG: TBC-domain GAPs for Rab GTPases accelerate GTP hydrolysis by a dual-finger mechanism. Nature 2006, 442:303-306.
54. Matoskova B, Wong WT, Seki N, Nagase T, Nomura N, Robbins KC, Di Fiore PP: RN-tre identifies a family of tre-related proteins displaying a novel potential protein binding domain. Oncogene 1996, 12:2563-2571.

55. Wiejak J, Wyroba E: Dynamin: characteristics, mechanism of action and function. Cell Mol Biol Lett 2002, 7:1073-1080.

56. Sever S: Dynamin and endocytosis. Curr Opin Cell Biol 2002, 14:463-467.

57. Damke H: Dynamin and receptor-mediated endocytosis. FEBS Lett 1996, 389:48-51.

58. Bucci C, Parton RG, Mather $I H$, Stunnenberg H, Simons K, Hoflack B, Zerial $M$ : The small GTPase rab5 functions as a regulatory factor in the early endocytic pathway. Cell 1992, 70:715-728.

59. Stenmark H, Parton RG, Steele-Mortimer O, Lutcke A, Gruenberg J, Zerial M: Inhibition of rab5 GTPase activity stimulates membrane fusion in endocytosis. Embo J 1994, 13:1287-1296.

60. van der Bliek AM, Meyerowitz EM: Dynamin-like protein encoded by the Drosophila shibire gene associated with vesicular traffic. Nature 1991, 351:411-414.

61. Chen MS, Obar RA, Schroeder CC, Austin TW, Poodry CA, Wadsworth SC Vallee RB: Multiple forms of dynamin are encoded by shibire, a Drosophila gene involved in endocytosis. Nature 1991, 351:583-586.

62. Pelissier A, Chauvin JP, Lecuit T: Trafficking through Rab11 endosomes is required for cellularization during Drosophila embryogenesis. Curr Biol 2003, 13:1848-1857.

63. Ramaswami M, Krishnan KS, Kelly RB: Intermediates in synaptic vesicle recycling revealed by optical imaging of Drosophila neuromuscular junctions. Neuron 1994, 13:363-375.

64. Lock JG, Stow JL: Rab11 in recycling endosomes regulates the sorting and basolateral transport of E-cadherin. Mol Biol Cell 2005, 16:1744-1755

65. Emery G, Hutterer A, Berdnik D, Mayer B, Wirtz-Peitz F, Gaitan MG, Knoblich JA: Asymmetric Rab 11 endosomes regulate delta recycling and specify cell fate in the Drosophila nervous system. Cell 2005, 122:763-773.

66. Jones MC, Caswell PT, Norman JC: Endocytic recycling pathways: emerging regulators of cell migration. Curr Opin Cell Biol 2006, 18:549-557.

67. Jekely G, Sung HH, Luque CM, Rorth P: Regulators of endocytosis maintain localized receptor tyrosine kinase signaling in guided migration. Dev Cell 2005, 9:197-207.

68. White DP, Caswell PT, Norman JC: alpha v beta3 and alpha5beta1 integrin recycling pathways dictate downstream Rho kinase signaling to regulate persistent cell migration. J Cell Biol 2007, 177:515-525.

69. Bretscher MS: Endocytosis and recycling of the fibronectin receptor in CHO cells. Embo / 1989, 8:1341-1348.

70. Woods AJ, White DP, Caswell PT, Norman JC: PKD1/PKCmu promotes alphavbeta3 integrin recycling and delivery to nascent focal adhesions. Embo J 2004, 23:2531-2543.

71. Shaye DD, Casanova J, Llimargas M: Modulation of intracellular trafficking regulates cell intercalation in the Drosophila trachea. Nat Cell Biol 2008, 10:964-970.

72. Blankenship JT, Fuller MT, Zallen JA: The Drosophila homolog of the Exo84 exocyst subunit promotes apical epithelial identity. J Cell Sci 2007, 120:3099-3110.

73. Trommsdorff M, Gotthardt M, Hiesberger T, Shelton J, Stockinger W, Nimpf J, Hammer RE, Richardson JA, Herz J: Reeler/Disabled-like disruption of neuronal migration in knockout mice lacking the VLDL receptor and ApoE receptor 2. Cell 1999, 97:689-701.

74. D'Arcangelo G, Homayouni R, Keshvara L, Rice DS, Sheldon M, Curran T: Reelin is a ligand for lipoprotein receptors. Neuron 1999, 24:471-479.

75. Dulabon L, Olson EC, Taglienti MG, Eisenhuth S, McGrath B, Walsh CA, Kreidberg JA, Anton ES: Reelin binds alpha3beta1 integrin and inhibits neuronal migration. Neuron 2000, 27:33-44.

76. Schmid RS, Jo R, Shelton S, Kreidberg JA, Anton ES: Reelin, integrin and DAB1 interactions during embryonic cerebral cortical development. Cereb Cortex 2005, 15:1632-1636.

doi: $10.1186 / 1756-6606-3-19$

Cite this article as: Houalla et al., Rab-mediated vesicular transport is required for neuronal positioning in the developing Drosophila visual system Molecular Brain 2010, 3:19 